\title{
Persepsi Mahasiswa PPKn Tentang Pelaksanaan dan Kebijakan Tunggal di Universitas Negeri Padang
}

\author{
Rezki Putra Yanni, Aina, Suryanef \\ Program Studi Pendidikan Pancasila Dan Kewarganegaraan \\ Universitas Negeri Padang \\ E-mail: rezkipeyegp@gmail.com
}

\begin{abstract}
ABSTRAK
Beredarnya Peraturan Menteri Pendidikan dan Kebudayaan Republik Indonesia No 55 Tahun 2013 tentang Biaya Kuliah Tunggal dan Uang Kuliah Tunggal yang bertujuan untuk meringankan biaya pendidikan bagi semua mahasiswa yang kuliah di perguruan tinggi negeri seluruh indonesia. Hal tersebut dikarenakan uang kuliah disesuaikan dengan kondisi ekonomi orang tua. Sejak pemberlakuan kebijakan tersebut tahun 2013 di Universitas Negeri Padang menimbulkan berbagai macam persepsi dikalangan mahasiswa.

Penelitian ini bertujuan untuk mengetahui persepsi mahasiswa PPKn tentang pelaksanaan dan kebijakan uang kuliah tunggal dari segi kebijakan, cara penetapan besaran UKT, besaran UKT, dan dampak UKT dengan menggunakan metode deskriptif kuantitatif. Subjek penelitian ini yaitu kebijakan UKT, cara penetapan UKT, besaran UKT, dan dampak UKT. Populasi penelitian yaitu mahasiswa PPKn tahun 2013-2016 yang berjumlah 424 orang. Pengambilan sampel yang digunakan adalah simple random sampling sehingga diperoleh 62 orang. Jenis data adalah data primer dan data sekunder yang diperoleh dari kuesioner dan dokumentasi. Data yang dikumpulkan tersebut dianalisis dengan langkah verifikasi data, skoring, klasifikasi dan tabulasi data, menghitung rata-rata jawaban responden dan menghitung persentase masing-masing kategori jawaban. Kemudian peneliti menginpretasikan dari hasil analisis data tersebut

Berdasarkan hasil penelitian, persepsi mahasiswa PPKn tentang pelaksanaan dan kebijakan Uang Kuliah Tunggal di Universitas Negeri Padang memberikan gambaran bahwa kebijakan tersebut dinilai cukup efektif. Namun demikian perlu ditingkatkkan sosialisasinya terhadap mahasiswa. Untuk pelaksanaanya, harus dimaksimalkan supaya tepat sasaran dan optimal.
\end{abstract}

\section{Kata kunci: Persepsi, Kebijakan, Uang Kuliah Tunggal}

\author{
ABSTRACT \\ The Distribution of Regulation of the Minister of Education and Culture of the \\ Republic of Indonesia No. 55 Year 2013 on Single Tuition Fee and Single Tuition Fee which \\ aims to alleviate the cost of education for all students who study in public universities \\ throughout Indonesia. This is because the tuition is adjusted to the economic conditions of \\ parents. Since the enactment of the policy in 2013 at State University of Padang raises \\ various perceptions among students. \\ This study aims to determine perceptions of KDP students about the \\ implementation and policy of single tuition in terms of policy, how to determine the amount \\ of UKT, the amount of UKT, and the impact of UKT by using descriptive quantitative
}


method. The subjects of this research are UKT policy, the determination of UKT, the magnitude of UKT, and the impact of UKT. The population of research is the students of PPKn year 2013-2016 which amounted to 424 people. Sampling used is simple random sampling so that obtained 62 people. Data types are primary data and secondary data obtained from questionnaires and documentation. The data collected were analyzed by data verification, scoring, classification and tabulation of data, calculate the average respondent's answer and calculate the percentage of each answer category. Then the researchers interpreted the results of the data analysis.

Based on the research result, PPKn student perception about implementation and policy of Single Tuition at State University of Padang gives an idea that the policy is considered quite effective. However, it needs to be socialized to the students. For the implementation, must be maximized so that the right target and optimal.

\section{Keywords: Perception, Policy, Single Tuition}

\section{PENDAHULUAN}

Uang Kuliah Tunggal (UKT) merupakan salah satu kebijakan pemerintah yang diberlakukan untuk perguruan tinggi negeri. Hal yang sampai sekarang ini masih menimbulkan masih pro dan kontra di kalangan mahasiswa perguruan tinggi negeri adalah tentang kebijakan Uang Kuliah Tunggal (UKT) tersebut. Uang Kuliah Tunggal ini dituangkan dalam Peraturan Menteri Pendidikan dan Kebudayaan Republik Indonesia Nomor 55 Tahun 2013 tentang Biaya Kuliah Tunggal dan Uang Kuliah Tunggal pada Perguruan Tinggi Negeri di Lingkungan Kementerian Pendidikan dan Kebudayaan. Berdasarkan peraturan tersebut dikatakan bahwa yang dimaksud dengan Uang Kuliah Tunggal adalah sebagian biaya kuliah tunggal yang ditanggung setiap mahasiswa berdasarkan kemampuan ekonominya. Sedangkan Biaya Kuliah Tunggal merupakan keseluruhan biaya operasional per mahasiswa per semester pada program studi di perguruan tinggi negeri. Biaya kuliah tunggal digunakan sebagai dasar penetapan biaya yang dibebankan kepada mahasiswa, masyarakat dan Pemerintah

Sistem Uang Kuliah Tunggal merupakan produk dari kebijakan publik dibidang pendidikan yang dibuat oleh pemerintah. Udoji dalam Solichin (2015: 15) bahwa kebijakan adalah suatu tindakan bersanksi dalam yang mengarah pada suatu tujuan tertentu yang saling berkaitan dan mempengaruhi sebagian besar masyarakat.

Dapat diketahui bahwa pembuatan kebijakan publik (public policy making) melibatkan pemerintah, dengan cara tertentu sebagai aktor pembuatan kebijakan tersebut. Gerston dalam Solichin (2015: 16) menegaskan bahwa semua pembuatan kebijakan melibatkan pemerintah dalam beberapa cara. Itulah sebabnya kebijakan dalam bentuk apapun dan untuk merealisasikan tujuan apapun, akan diberi makna sebagai kebijakan publik jika sebagian atau seluruhnya digagas, dikembangkan dan dirumuskan, atau dibuat oleh instasiinstansi, seta melibatkan (langsung atau tidak langsung) pejabat-pejabat pemerintah. Selain itu kelompok- 
kelompok kepentingan juga dapat menjadi aktor dalam menentukan arah rumusan kebijakan publik itu sendiri

Universitas Negeri Padang atau lebih dikenal dengan UNP, sebagai salah satu perguruan tinggi negeri di Sumatera Barat juga harus menerapkan kebijakan tersebut. Kebijakan tersebut mulai terapkan pada penerimaan mahasiswa baru tahun akademik 2013. Dan hal tersebut masih berjalan hingga penerimaan mahasiswa baru di tahun 2016.

Dalam menetapkan uang kuliah untuk mahasiswa baru Universitas Negeri Padang melakukan wawancara terhadap mahasiswa baru dan orang tua atau wali mereka. Penetapan besaran uang kuliah tunggal mahasiswa baru disesuaikan kondisi ekonomi para orang tua mahasiswa baru. Dari hasil wawancara tersebut kemudian ditentukan kategori uang kuliah tunggal mahasiswa baru.

Namun dalam penetapan besaran uang kuliah tunggal terhadap mahasiswa baru menimbulkan berbagai keluhan dikalangan mahasiswa baru sendiri, dan juga menjadi keluhan bagi orang tua mahasiswa sebagai orang yang bertanggung jawab akan uang kuliah anaknya.

Hal tersebut dikarenakan besaran uang kuliah tunggal yang mereka harus bayarkan dinilai terlalu besar dan tidak tepat sasaran. Selain itu, bagi mahasiswa yang yang mempunyai pekerjaan orang tua sebagai Pegawai Negeri Sipil penetapan besaran uang kuliah tunggal yang harus mereka bayar hana berpedoman pada slip gaji orang tua tanpa melihat jumlah tanggungan dari orang tua.
Untuk mahasiswa yang masuk jalur mandiri tahun 2014, penetapan uang kuliah tunggal mereka langsung ditetapkan saja tanpa melalui proses wawancara. Hal ini dirasakan sebagai suatu ketidakadilan bagi mereka. Padahal yang mereka ketahui uang kuliah tunggal ditetapkan berdasarkan kondisi ekonomi orang tua.

Adanya kecemburuan sosial yang terjadi antara mahasiswa dengan jalur masuk SNMPTN, jalur SBMPTN, dan jalur Mandiri. Jalur masuk SNMPTN dan jalur masuk SBMPTN merasakan suatu ketidakadilan. Mereka yang masuk dengan jalur SNMPTN dan jalur SBMPTN yang dianggap memilki kemampuan lebih, malah memiliki Uang Kuliah Tunggal yang tinggi. Namun sebaliknya, mahasiswa dengan jalur Mandiri memilki Uang Kuliah Tunggal yang dikategorikan rendah dibandingkan dengan mahasiswa jalur masuk SNMPTN dan jalur masuk SBMPTN. Karena faktanya, mahasiswa jalur masuk Mandiri merupakan mahasiswa jalur terakhir masuk Universitas Negeri Padang.

Dalam penelitian yang dilakukan oleh Prof. Dr. Jamal Wiwoho, S.H, M.Hum yang berjudul "UKT : Ability To Pay Dalam Sistem Pembayaran Kuliah" diketahui bahwa banyak manfaat yang diperoleh dengan berlakunya UKT. Dari penelitian tersebut dapat disimpulkan bahwa:

1. UKT menepis anggapan mahalnya biaya kuliah di PTN karena meringankan biaya pendidikan.

2. UKT memberikan kepastian seberapa jumlah uang yang harus dikeluakan selama kuliah 
3. Dengan adanya UKT dapat dicegah adanya berbagai pungutan yang tidak jelas dan dilakukan oleh oknum-oknum kampus.

Melihat permasalahan tersebut, selanjutnya peneliti ingin melihat bagaimana persepsi mahasiswa Pendidikan Pancasila dan Kewarganegaraan tentang pelaksanaan Uang Kuliah Tunggal di Universitas Negeri Padang. Dengan melihat bagaimana persepsi mahasiswa Pendidikan Pancasila dan Kewarganegaraan tentang pelaksanaan Uang Kuliah Tunggal di Universitas Negeri Padang, maka diharapkan dapat menjadi masukanmasukan bagi pihak universitas sendiri dalam menetapkan besaran Uang Kuliah Tunggal mahasiswa baru Universitas Negeri Padang. Untuk itu, penulis tertarik untuk melakukan penelitian tentang bagaimana "Persepsi Mahasiswa PPKn Tentang Pelaksanaan dan Kebijakan Uang Kuliah Tunggal di Universitas Negeri Padang"

\section{METODE PENELITIAN}

Penelitian ini menggunakan metode deskriptif kuantitatif. Subjek penelitian ini yaitu kebijakan UKT, cara penetapan UKT, besaran UKT, dan dampak UKT. Populasi penelitian yaitu mahasiswa PPKn tahun 20132016 yang berjumlah 424 orang. Pengambilan sampel yang digunakan adalah simple random sampling sehingga diperoleh 62 orang. Jenis data adalah data primer dan data sekunder yang diperoleh dari kuesioner dan dokumentasi. Data yang dikumpulkan tersebut dianalisis dengan langkah verifikasi data, skoring, klasifikasi dan tabulasi data, menghitung rata-rata jawaban responden dan menghitung persentase masing-masing kategori jawaban. Kemudian peneliti menginpretasikan dari hasil analisis data tersebut.

\section{HASIL DAN PEMBAHASAN}

Penelitian ini membahas persepsi mahasiswa PPKn tentang pelaksanaan dan kebijakan Uang Kuliah Tunggal dari beberapa segi yaitu:

\section{Kebijakan Uang Kuliah Tunggal \\ Persepsi mahasiswa PPKn} terhadap kebijakan dan pelaksanaan uang kuliah tunggal di UNP dari segi kebijakan UKT, memberikan gambaran bahwa mahasiswa menyatakan sudah mengetahui tentang pemberlakuan kebijakan Uang Kuliah Tunggal di UNP. Tetapi pemahaman mereka mengenai kebijakan Uang Kuliah Tunggal tersebut masih sangat minim karena tidak ada sosialisasi dari birokrat UNP tentang kebijakan Uang Kuliah Tunggal tersebut. Mereka hanya mendengar melalui media massa bahwa adanya pemberlakuan sistem Uang Kuliah Tunggal di UNP. Hal tersebut mengakibatkan timbulnya berbagai macam persepsi diantara mereka.

Persepsi manusia terdapat perbedaan sudut pandang dalam penginderaan. Ada yang mempersepsikan sesuatu itu baik atau persepsi yang positif maupun persepsi negatif yang akan mempengaruhi tindakan manusia yang tampak atau nyata. Bimo (2004: 70) menyatakan bahwa persepsi merupakan suatu proses pengorganisasian, penginterpretasian terhadap 
stimulus yang diterima oleh organisme atau individu sehingga menjadi sesuatu yang berarti, dan merupakan aktivitas yang integrated dalam diri individu. Respon sebagai akibat dari persepsi dapat diambil oleh individu dengan berbagai macam bentuk stimulus mana yang akan mendapatkan respon dari individu tergantung pada perhatian individu yang bersangkutan.

2. Dari Segi Cara Penetapan Besaran Uang Kuliah Tunggal

Persepsi mahasiswa PPKn terhadap kebijakan dan pelaksanaan uang kuliah tunggal di UNP dari segi cara penetapan besaran UKT. Dalam hal ini, penetapan besaran UKT mahasiswa menimnbulkan pro dan kontra dikalangan mahasiswa itu sendiri. Cara penetapan besaran UKT ditetapkan melalui proses wawancara. Proses wawancara tersebut dilakukan dengan tujuan untuk mengetahui bagaimana kondisi ekonomi mahasiswa tersebut. Selain itu juga dilihat jumlah tanggungan dari keluarga. Dari hasil wawancara tersebut kemudian baru ditetapkan seberapa besar Uang Kuliah Tunggal yang seharusnya dibayarkan oleh mahasiswa tersebut sesuai dengan kondisi ekonominya. Bagi mahasiswa yang mempunyai orang tua bekerja sebagai PNS baik salah satu maupun kedua-duanya mendapatkan UKT di atas dua juta rupiah. UKT memang uang kuliah tunggal yang dibayarkan setiap semesternya tanpa ada pungutan kuliah lainnya. Walaupun demikian, masih banyak juga mahasiswa yang keberatan dengan besaran UKT yang mereka terima terutama yang mendapatkan UKT empat juta rupiah. Hal tersebut dikarenakan mereka merasa uang kuiah yang mereka terima terlalu besar

Konsep kebijakan dipaparkan Jenkins dalam Solichin (2015: 15) memformulasikan kebijakan publik sebagai keputusan yang saling berkaitan yang diambil oleh seorang aktor politik, berkaitan dengan tujuan yang telah dipilih beserta cara-cara untuk mencapainya dalam suatu situasi. Keputusan-keputusan itu pada dasar masih berada dalam batasbatas kewenangan kekuasaan aktor tersebut. Selain itu, Lemieux dalam Solichin (2015: memformulasikan kebijakan publik sebagai produk aktivitas-aktivitas yang bertujuan untuk memecahkan masalah publik yang terjadi pada lingkungan tertentu yang dilakukan oleh aktor-aktor politik yang hubungannya terstruktur. Keseluruhan proses aktivitas tersebut berlangsung sepanjang waktu.

3. Dari Segi Besaran Uang Kuliah Tunggal

Persepsi mahasiswa PPKn terhadap kebijakan dan pelaksanaan uang kuliah tunggal di UNP dari segi besaran UKT. Seperti halnya di atas, penetapan besaran UKT yang diterima oleh mahasiswa menuai pro dan kontra. Mereka melihat adanya perbedaan mencolok besaran uang kuliah antara mahasiswa mampu dan kurang mampu. Tetapi ada juga mahasiswa yang merasakan bahwa 
besaran uang kuliah yang mereka terima sudah sesuai dengan kondisi ekonomi orang tuanya. Untuk mendapatkan besaran Uang Kuliah Tunggal pada tingkatan yang lebih rendah mahasiswa berusaha untuk tidak jujur dalam melakukan wawancara UKT tersebut.Mereka banyak mendengar dari para senior sebelum diberlakukan sistem UKT, uang kuliah lebih merata dan adil. Perbedaan uang kuliah hanya dibedakan berdasarkan jalur masuk mahasiswa saja. hal ini menimbulkan pemikiran oleh mahasiswa bahwa sebelum ada sistem UKT lebih baik. Kecemburuan sosial juga terjadi antara mahasiswa jalur masuk SNMPTN, SNMPTN, dan Mandiri karena seharusnya uang kuliah mereka dibedakan. Tidak hanya itu mereka terkadang merasa iri terhadap kampus swasta yang mempunyai uang kuliah lebih rendah dari besaran UKT mereka dan pernah berpikir untuk pindah kuliah.

Menurut Suharno (2010: 52) proses pembuatan kebijakan adalah pekerjaan yang rumit dan kompleks. Para administrator satu organisasi institusi dituntut memiliki tanggung jawab dan kemauan, serta kemampuan atau keahlian, sehingga dapat membuat kebijakan dengan resiko yang diharapkan (intended risks) maupun yang tidak diharapkan (unintended risks). Pembuatan kebijakan dipengaruhi oleh beberapa faktor. Faktor-faktor yang mempengaruhi pembuatan kebijakan adalah yaitu (a) adanya pengaruh tekanantekanan dari luar (b) adanya pengaruh kebiasaan lama (c) adanya pengaruh sifat-sifat pribadi (d) adanya pengaruh dari kelompok luar (e) adanya pengaruh keadaan masa lalu.

\section{Dari Segi Dampak Uang Kuliah Tunggal}

Persepsi mahasiswa PPKn terhadap kebijakan dan pelaksanaan uang kuliah tunggal di UNP dari segi dampak UKT. Pemberlakuan sistem UKT memberikan dampak terhadap mahasiswa dan para orang tuanya. Hal ini dapat diketahui dari aksi mahasiswa di UNP yang mencoretcoret dinding dalam menyampaikan aspirasi mereka terhadap UKT tersebut. Selain itu, BEM UNP juga menerima aspirasi mahasiswa yang memiliki besaran UKT tinggi agar bisa disampaikan kepada birokrat kampus dengan harapan dapat ditinjau kembali. Banyak mahasiswa yang meminta melakukan peninjauan kembali terhadap Uang Kuliah Tunggal yang mereka terima karena dinilai terlalu besar. Harapan mahasiswa adalah ditahun selanjutnya kembali sistem uang kuliah seperti biasanya agar uang kuliah mahasiswa merata dan lebih adil. Dan diharapkan tidak adalagi kecemburuan sosial yang terjadi dikalangan mahasiswa. Implementasi suatu kebijakan akan menimbulkan akibat-akibat atau dampak (langsung) yang benar-benar dirasakan oleh masyarakat, baik yang diharapkan (intended) maupun yang tidak diharapkan (unintented), sebagai konsekuensi logis dari adanya tindakan atau tidak adanya tindakan pemerintah dalam bidang-bidang atau masalah- 
masalah tertentu yang ada dalam masyarakat.

\section{KESIMPULAN}

Dari hasil penelitian yang telah peneliti lakukan,pelaksanaan kebijakan tersebut menghasilkan kesimpulan seperti di bawah ini:

1. Persepsi mahasiswa PPKn terhadap pelaksanaan dan kebijakan uang kuliah tunggal di Universitas Negeri Padang dari segi kebijakan UKT, memberikan gambaran bahwa mahasiswa dan para orang tua mereka sudah mengetahui adanya pemberlakuan kebijakan UKT di Universitas Negeri Padang tetapi mereka kurang mengetahui maksud sistem UKT itu sendiri. Hal ini dikarenakan sosialisasi dari sistem UKT yang minim sehingga menimbulkan pro dan kontra dikalangan mahasiswa.

2. Persepsi mahasiswa PPKn terhadap kebijakan dan pelaksanaan uang kuliah tunggal di UNP dari segi cara penetapan besaran UKT. Dalam hal ini, cara penetapan besaran UKT ditetapkan melalui proses wawancara untuk mengetahui kondisi ekonomi orang tua. Walaupun demikian, masih banyak juga mahasiswa yang keberatan dengan besaran UKT yang mereka terima.

3. Persepsi mahasiswa PPKn terhadap kebijakan dan pelaksanaan uang kuliah tunggal di UNP dari segi besaran UKT. Penetapan besaran UKT yang diterima oleh mahasiswa masih menuai pro dan kontra karena merasa besaran UKT yang tidak tepat sasaran atau terlalu besar. Kecemburuan sosial juga terjadi antara mahasiswa jalur masuk SNMPTN, SNMPTN, dan Mandiri karena seharusnya uang kuliah mereka dibedakan. Tidak hanya itu mereka terkadang merasa iri terhadap kampus swasta yang mempunyai uang kuliah lebih rendah dari besaran UKT mereka.

4. Pemberlakuan sistem UKT memberikan dampak terhadap mahasiswa dan para orang tuanya. Harapan mahasiswa adalah ditahun selanjutnya kembali sistem uang kuliah seperti biasanya karena rasakan lebih adil dan merata. Sebenarnya disisi lain sistem UKT ini memberikan kesempatan kepada mahasiswa kurang mampu untuk dapat melanjutkan pendidikan sampai ke jenjang perguruan tinggi.

\section{Saran}

1. Semua pihak yang terlibat dalam pelaksanaan uang kuliah tunggal sebaiknya bekerja sama supaya pelaksanaan kebijakan ini berjalan dengan baik sesuai yang diharapkan.

2. Proses penentuan tingkatan UKT untuk masng-masing mahasiswa sebaiknya lebih dipertimbangkan supaya tidak ada lagi terjadi hal-hal yang 
Persepsi Mahasiswa PPKn..

memberatkan bagi Kebijakan. Jakarta: Bumi Aksara mahasiswa.

3. Mahasiawa atau calon mahasiswa sebaiknya update informasi mengenai kebijakan sistem UKT ini agar tidak lagi menimbulkan pro dan kontra dikalangan mahasiswa.

\section{DAFTAR PUSTAKA}

\section{Buku}

Bimo Walgito. 2004. Pengantar Psikologi Umum. Jogjakarta: Andi Offset

Lijan Poltak Sinambela. 2014. Metodologi

Penelitian Kuantitatif. Jogjakarta.

Graha Ilmu

Solichin Abdul Wahab.2015.Analisis

Suharno. 2010. Dasar-Dasar Kebijakan

Publik. Jogjakarta. UNY Press

Suharsimi Arikunto. 2010. Manajemen

Penelitian. Jakarta. Rineka Cipta

Dokumen Resmi

Permendikbud No.55 Tahun 2013 Biaya

Kuliah

Kuliah Tunggal dan Uang

Tunggal

\section{Akses Internet}

Jamal Wiwoho.2013.UKT:Ability To Pay

Dalam Sistem Pembayaran Kuliah.Surakarta.Sidiknas 
